\title{
TOMÁS DE AQUINO INTÉRPRETE DA TRADIÇÃO EUDAIMONISTA, SEGUNDO MANUSCRITO INÉDITO DE HENRIQUE CLÁUDIO DE LIMA VAZ
}

Thomas Aquinas' interpretation of the Eudaimonist tradition, according to an unpublished manuscript of Henrique Cláudio de Lima Vaz

Juvenal Savian Filho *

Resumo: Visa-se apresentar aqui a exegese inédita, feita por Henrique Cláudio de Lima Vaz, da posição tomasiana que articula a beatitude e a destinação do espírito segundo a especificidade da "personalidade científica de Santo Tomás", a qual, como descreve o próprio Lima Vaz, é formada por uma exploração de todas as grandes correntes de ideias que confluíram para o século XIII, fundamentalmente a aliança ambígua de Aristóteles entre platonismo e empirismo, o neoplatonismo, com as mediações árabes, e a tradição bíblica que forneceu a Tomás um novo fermento para ampliar a fenomenologia aristotélica da beatitude em um movimento inteiramente natural, convergente para $o$ alto e que se estreita, porém, à medida que avança, chegando a um vértice no qual o Universo é síntese inteligível no espírito, o qual, por sua vez, atinge seu Princípio, o seu próprio Bem, íntimo e transcendente.

Palavras-chave: Henrique Vaz. Thomas Aquinas. Eudaimonismo. Transcendência. Beatidude.

Abstract: This paper aims to present Henrique Cláudio de Lima Vaz's original exegesis, concerning Saint Thomas' position that articulates the concept of beatitude and the destination of the spirit, according to the specific nature of his "scientific personality". Lima Vaz describes it as a mix of interest in all the

\footnotetext{
* Professor do Departamento de Filosofia da Universidade Federal de São Paulo (UFESP).
} Artigo recebido em 26/02/2021 e aprovado para publicação em 28/02/2021. 
main currents of ideas prevailing in the thirteenth century, not only Aristotle's ambiguous relationship between Platonism and empiricism, but also Neoplatonism, Arabian influences, and the biblical tradition that provided St Thomas with a new leaven, allowing him to extend the Aristotelian phenomenology of beatitude in a completely natural movement, converging towards the top and narrowing as it progresses, in order to reach an apex in which the Universe becomes an intelligible synthesis in the human spirit that, in turn, finds its Principle, its own intimate and transcendent Good.

Keywords: Henrique Vaz. Thomas Aquinas. Eudaimonism. Transcendence. Beatidude.

\section{Breve histórico do manuscrito de Lima Vaz}

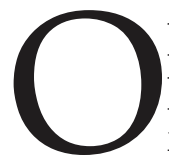
presente estudo é uma apresentação, em forma de simples e parcial paráfrase (na esperança de que venha à luz uma publicação em forma de livro), do conteúdo do manuscrito inédito de Henrique Cláudio de Lima Vaz, intitulado O problema da beatitude e a destinação do espírito segundo Santo Tomás, conservado na Faculdade Jesuíta de Filosofia e Teologia (FAJE), Belo Horizonte, armário 2, gaveta 8 .

A redescoberta do manuscrito só foi possível graças ao cuidado da comunidade jesuíta, especialmente do zeloso Pe. João Augusto Anchieta Amazonas Mac Dowell, que, correspondendo imediatamente ao pedido do autor deste artigo, ${ }^{1}$ perseguiu a pista dada pelo próprio Lima Vaz em um depoimento publicado em 1976, ${ }^{2}$ quando afirma ter escrito uma dissertação para conclusão de curso e obtenção da Licenciatura em Teologia, na Pontifícia Universidade Gregoriana de Roma (1950), na qual fazia uma releitura da Ética nicomaqueia de Aristóteles e das primeiras questões da Secunda Secundae (a Segunda Parte da Parte II) da Suma de teologia de Tomás de Aquino.

Antes de reencontrá-lo na biblioteca da própria FAJE, Pe. Mac Dowell pensara que a melhor maneira de encontrar o manuscrito seria solicitá-lo à biblioteca da Universidade Gregoriana, coisa que este autor também já havia feito no início dos anos 2000, porém sem sucesso, uma vez que o material encontra-se em um arquivo ao qual a universidade não permite

\footnotetext{
${ }^{1}$ Seja-me permitido considerar este artigo uma homenagem afetuosa de minha parte ao Pe. Vaz, a quem lastimavelmente nunca encontrei, mas que contribuiu de maneira essencial para a expansão dos horizontes de minha existência. Aliás, nos obscuros tempos que vivemos nos anos 2020-2021, no mundo inteiro, mas especialmente em nosso país, mostra-se de extrema lucidez a sua afirmação de que, no Brasil atual, a vocação filosófica vem carregada de enorme responsabilidade social.

${ }^{2}$ Cf. LIMA VAZ, H. C. Meu depoimento. In: LADUSÃNS, S. (Org.). Rumos da filosofia atual no Brasil em auto-retratos. São Paulo: Loyola, 1976, p. 302-303.
} 
acesso. Diante da resposta negativa da Universidade Gregoriana, Pe. Mac Dowell, providencialmente, encontrou uma cópia do manuscrito conservada nos próprios arquivos do Memorial Padre Vaz, de Belo Horizonte. Agora, redescoberta, ela pode ser consultada livremente. ${ }^{3}$

A novidade trazida pelo manuscrito de Lima Vaz consiste na análise da leitura tomasiana da Ética nicomaqueia tal como registrada nas primeiras questões da Secunda Secundae com as chaves de interpretação oferecidas pelo trabalho do jesuíta Henri de Lubac (1896-1991), cardeal tardio, homem de inestimável erudição, verdadeiro missionário do diálogo cristão com a cultura, ou, mais do que isso, da promoção do encontro da experiência cristã com experiências não cristãs (incluindo o ateísmo) naquilo em que todas elas revelam de autenticamente humano.

Como costumam dizer os historiadores do cristianismo contemporâneo, entre os centros de efervescência do pensamento cristão na primeira metade do século XX (como o círculo reunido em torno de Karl Rahner, 1904-1984, na Alemanha e na Áustria, ou de Hans Urs von Balthasar, 1905-1988, na Suíça) estavam o convento dominicano Le Saulchoir, inicialmente instalado em Kain (Bélgica) e depois em Paris, e o grupo jesuíta de Fourvière, bairro de Lyon (França). Os dominicanos de Paris reuniam-se, entre outros, em torno dos teólogos Marie-Dominique Chenu (1895-1990) e Marie-Joseph Congar (19041995), também cardeal tardio, e dedicavam-se sobretudo aos estudos históricos de Tomás de Aquino, assim como à articulação entre teologia e história, em recuperação direta da herança patrística, de modo especial Santo Agostinho, para quem a historicidade da experiência cristã é um fato. É nessa mesma linha que, na Faculdade Católica de Teologia da Universidade de Estrasburgo (França), Congar, Rahner, Von Balthasar, Joseph Ratzinger (1927-) e outros (entre eles o teólogo brasileiro Francisco Catão, 1928-2020, então secretário de Congar) reunir-se-ão para debater formas de contribuir com as reflexões preparativas do Concílio Vaticano II. Já os jesuítas do grupo de Fourvière reuniam-se em torno de Henri de Lubac e, beneficiando-se dos estudos históricos sobre Santo Tomás desenvolvidos pelos dominicanos de Paris (e, mesmo antes deles, pelo historiador da filosofia e da teologia católica Martin Grabmann, 1875-1949, o lógico Józef Maria Bochenski, 1902-1995, e mesmo o historiador da filosofia Etienne Gilson, 1884-1978), dedicavam-se a pensar cristãmente o mundo contemporâneo e o encontro das culturas, por meio do estudo sistemático do pensamento de Maurice Blondel (1861-1949) e das

\footnotetext{
${ }^{3}$ Talvez o manuscrito não seja acessível ao público na Universidade Gregoriana por ter sido recebido com relutância, embora aprovado, pelo também jesuíta Charles Boyer, então prefeito dos estudos da mesma universidade (cf. LIMA VAZ, Meu depoimento, op. cit., p. 303). Como se verá pelas razões apresentadas neste artigo, certamente a relutância do Pe. Boyer se devia à abordagem adotada por Lima Vaz, na linha dos estudos sobre o Tomás de Aquino histórico, e não do tomismo "oficial" e pretensamente "ortodoxo", "perene" ou "imutável", que tinha em Boyer um de seus mais fortes representantes.
} 
intuições e pesquisas histórico-teóricas do próprio De Lubac, sobretudo sua releitura de Tomás de Aquino em chave histórica, propriamente tomasiana, e não neotomista.

Segundo recorda com emoção Lima Vaz, a leitura "com fremente e concentrada atenção" ${ }^{4}$ de Sobrenatural - Estudos históricos, de De Lubac, ${ }^{5}$ canalizou os maiores estímulos intelectuais que recebeu na sua época de estudos teológicos em Roma, levando-o também à leitura rigorosa de Blondel. Com efeito, a nouvelle théologie (nova teologia), encarnada por De Lubac, Congar, Chenu, Von Balthasar e Ratzinger, defendia um retorno às fontes patrísticas ou à seiva mesma do cristianismo, com uma relativização, senão mesmo uma liquidação, da teologia escolástica e neoescolástica da Idade Moderna, a "teologia barroca", como costumava chamá-la Congar, entre cujos principais liquidadores estavam os jesuítas, no dizer do futuro cardeal, $^{6}$ embora essa teologia, por sua esterilidade espiritual e histórica, tenha por destino inescapável esvaziar-se a si mesma e autoliquidar-se a cada dia em que conseguir resistir ou voltar a vir à tona.

No quadro da nouvelle théologie, a obra Sobrenatural, publicada por De Lubac em 1946, punha a nu a história dos movimentos de ideias cristãs e não cristãs que, a partir do século $\mathrm{XV}$, levaram a tratar como óbvia a separação entre natureza e sobrenatural, separação esta que, de acordo com os resultados de suas pesquisas de fontes, é infiel às tradições cristãs mais antigas. Aliás, no artigo O mistério do sobrenatural, de 1949,7 De Lubac mostra que uma reflexão mais condizente com o ensino tradicional da Igreja levaria a afirmar a gratuidade da criação e da redenção, em correlação direta com uma forma positiva de pensar a relação entre imanência e transcendência, e não a insistir em algo como uma "natureza pura", separada do sobrenatural ou da graça. Essa ideia é por ele mais desenvolvida em Agostinismo e teologia moderna, de $1965,{ }^{8}$ no qual, ao estudar a controvérsia teológica com Baio e Jansênio, De Lubac conclui que, diante desses dois agostinianos "desorientados", os teólogos teriam feito melhor trabalho se tivessem repensado ou reinventado a ligação natural entre natureza e sobrenatural, em vez de opor a eles o sistema de uma "natureza pura". Dessa perspectiva, o livro O mistério do sobrenatural, também de $1965^{9}$ e

\footnotetext{
${ }^{4}$ LIMA VAZ, Meu depoimento, op. cit., p. 302.

${ }^{5}$ DE LUBAC, H. Surnaturel - Etudes historiques. Paris: Aubier-Montaigne, 1946. Reedição mais recente: Lethielleux, 2010.

${ }^{6}$ Cf. CONGAR, Y. Journal d'un théologien - 1946-1956. Ed. Etienne Fouilloux. Paris: Cerf, 2000, p. 24.

${ }^{7}$ DE LUBAC, H. Le mystère du surnaturel. Recherches de science religieuse 36/1 (1949) 80-121. Versão mais recente em: DE LUBAC, H. Théologie dans l'histoire - Vol. II (Questions disputées E Résistance au nazisme). Paris: Desclée de Brouwer, 1990, p. 71-107.

${ }^{8}$ DE LUBAC, H. Augustinisme et théologie moderne. Paris: Aubier-Montaigne, 1965. Reedição mais recente: Cerf, 2009.

${ }^{9}$ DE LUBAC, H. Le mystère du surnaturel. Paris: Aubier-Montaigne, 1965. Reedição mais recente: Cerf, 1999.
} 
de título homônimo ao do artigo de 1949, pode ser lido como uma tentativa de fazer ver como o pensamento pode retomar os fios afrouxados ou mesmo rompidos pela separação ocidental moderna entre natureza e finalidade, essência e história, teologia e filosofia, fé e razão. ${ }^{10}$

Completa esse quadro a formação que Lima Vaz recebera anos antes, em seus estudos filosóficos, quando se dedicou ao pensamento clássico, sobretudo Platão. Mais tarde, já em Roma, onde, além de seus estudos teológicos, doutorou-se em Filosofia, na mesma Pontifícia Universidade Gregoriana, debruçou-se também sobre o existencialismo de Sartre, ao qual teceu uma crítica da qual nunca voltaria atrás. Sua análise do mundo de então orientava-se mês a mês, como ele mesmo relembra, pela leitura da revista Esprit, ${ }^{11}$ quando encontra o personalismo de Emmanuel Mounier (1905-1950) e, alguns anos depois, elaborando certas decepções com o personalismo, a obra de Maurice Blondel. O personalismo o conduzira a seu primeiro contato com o marxismo, principalmente pelos debates de Mounier com os ideólogos do Partido Comunista francês e alguns "cristãos progressistas", como eram chamados. Na linha do pensamento do jesuíta Gaston Fessard (1897-1978), Lima Vaz, mesmo antes de estudar sistematicamente Marx, elaborou uma crítica do marxismo da qual também não mais se afastaria. Seu problema "apaixonante", ${ }^{12}$ no entanto, era e sempre continuou a ser, como se dizia no vocabulário da nouvelle théologie, o sobrenatural ou o Transcendente, instalado no coração do pensamento ocidental por Platão e pretensamente enxotado por Marx, os teólogos da "morte de Deus", da "revolução" ou da "festa". O pensamento de Hegel - outra das maiores especialidades de Lima Vaz - somente o atraía àquela época; será em seu retorno ao Brasil que, interessado pelas questões filosóficas mais atuais (da fenomenologia à filosofia da ciência), ele se verá na necessidade de galgar a montanha do pensamento hegeliano, esse "Império do Meio" entre a contemporaneidade e o mundo antigo-medieval. ${ }^{13}$ Lima Vaz não deixará, seja permitido dizê-lo, de jubilar com o racionalismo hegeliano, mas verá nele uma das raízes da atitude antitranscendência ou antissobrenatural moderna e contemporânea, algo que já intuía no tempo da redação de sua tese de doutorado em Filosofia, Contemplação e dialética nos diálogos platônicos. ${ }^{14}$

\footnotetext{
${ }^{10}$ Para uma visão introdutória do objeto essencial dos estudos de De Lubac a respeito do sobrenatural, bem como seu método, sua novidade, exigências e contribuições históricas, filosóficas, teológicas e culturais de modo geral, ver: VIGNAUX, P. Henri de Lubac - Surnaturel. Revue de l'histoire des religions 132 (1946) 225-226; CHANTRAINE, G. Surnaturel et destinée humaine dans la pensée occidentale selon Henri de Lubac. Revue des sciences philosophiques et théologiques 85/2 (2001) 299-312.

${ }^{11}$ Cf. LIMA VAZ, Meu depoimento, op. cit., p. 301-302.

${ }^{12}$ Idem, ibidem.

${ }^{13}$ Cf. idem, p. 305.

${ }^{14}$ LIMA VAZ, H. C. De contemplatione et dialectica in platonicis dialogis. Tese. Roma: Pontifícia Universidade Gregoriana, 1953. Tradução brasileira: Contemplação e dialética nos diálogos platônicos. Trad. Juvenal Savian Filho. São Paulo: Loyola, 2012.
} 
Esse quadro certamente não "explica" o estudo do comentário de Tomás de Aquino à ética aristotélica desenvolvido por Lima Vaz, mas permite situá-lo no movimento intelectual em que nasceu. Se o fizesse, a explicação resultante seria meramente exterior. Na contrapartida, evocá-lo possibilita enfatizar o caráter exegético-interpretativo do estudo de Lima Vaz, que, porém, não fez uma simples interpretação livre. Além disso, torna-se mais viável a avaliação do sentido de sua preocupação com o tema da destinação do espírito, que, por fim, manifesta a atualidade do pensamento tomasiano, na qual ele tanto insistia.

\section{Estrutura e metodologia do manuscrito}

O manuscrito de Lima Vaz estrutura-se em cinco partes: I. Introdução (14 laudas); II. Fenomenologia da beatitude (9 laudas); III. Teocentrismo da beatitude (38 laudas); IV. Natureza, espírito, Deus (10 laudas); V. Conclusão (7 laudas).

Quanto à metodologia de análise, Lima Vaz deixa entrever, de saída, que não considera Tomás de Aquino o autor de um sistema ou corpo completo de pensamento, com respostas ou indicativos de respostas para todos os problemas possíveis. ${ }^{15}$ Sem pretender elaborar um "discurso do método que se possa chamar tomista", ${ }^{16}$ Lima Vaz enuncia, no entanto, alguns elementos metodológicos de sua exegese. O primeiro deles é o reconhecimento de que os textos tomasianos, embora claros em si, integram-se no pensamento complexo de seu autor, personalidade científica que terá sistematizado o aristotelismo de Alberto Magno. Tal sistematização fará de Tomás de Aquino um "intuitivo poderoso e um gênio discursivo": ${ }^{17}$ como intuitivo, explorará a fundo todas as grandes correntes de ideias que confluíram para o século XIII (o aristotelismo e o platonismo, com suas mediações neoplatônicas e árabes, a teologia apofática e os dados científicos); como gênio discursivo, servir-se-á da lógica aristotélica para produzir conclusões nas quais "os dedutivos se deliciarão". ${ }^{18}$

É legítimo perguntar se o manuseio da lógica aristotélica não levaria a um cerceamento da liberdade intuitiva de nutrir interesse pelas mais variadas formas de pensamento. $\mathrm{O}$ empirismo aristotélico não estreitaria o campo de investigação daqueles que nele se inspiram?

\footnotetext{
${ }^{15}$ No que ele é acompanhado por grandes especialistas da obra tomasiana, entre eles Etienne Gilson, autor do clássico Le thomisme - Introduction à la philosophie de Saint Thomas d'Aquin (Paris: Vrin, 1945/2010).

${ }^{16}$ LIMA VAZ, H. C. O problema da beatitude e a destinação do espírito segundo Santo Tomás. Dissertação. Roma: Pontifícia Universidade Gregoriana, 1950, p. 1.

${ }^{17}$ Idem, p. 2.

${ }^{18}$ Idem, ibidem.
} 
Lima Vaz responde a essa pergunta lembrando que, na abordagem do pensamento de Tomás de Aquino, há um dado mais profundo, o fato de Tomás ser primeiramente teólogo, o que lhe dá extrema liberdade para buscar elementos que lhe permitam reelaborar, à sua maneira, o encontro das visões de mundo bíblica e helênica, na linha do longo e fecundo diálogo estabelecido desde o século II. Todavia, Tomás de Aquino não produz um pensamento eclético, mas, justamente guiado pelo rigor da lógica aristotélica, encontrará meios para abrir-se a outras formas de pensar e dizer, superando mesmo Aristóteles.

O problema da beatitude é um dos melhores exemplos para conhecer a originalidade de Tomás. Ao formulá-lo, Lima Vaz explicita um segundo elemento metodológico fundamental: um estudo que se pretenda fiel à letra e ao espírito de Tomás deve evitar o ponto de vista parcial e abstrato, comum em muitos estudos tomistas que ora são exclusivamente exegéticos, ora prevalentemente filosóficos e apriorísticos, ora, ainda, condicionados por posições teológicas prévia e rigidamente definidas. Nesse aspecto preciso, Lima Vaz reconhece os avanços dos estudos de Henri de Lubac e Henri Rondet (1898-1979), ${ }^{19}$ pondo-se em continuidade direta com ambos, embora não chegue exatamente aos mesmos resultados que eles. Pode-se também identificar, neste elemento metodológico, a influência dos estudos históricos desenvolvidos pelos dominicanos do convento Le Saulchoir, já mencionados aqui e aos quais Lima Vaz bem conhecia.

Como desenvolvimento desse primeiro dado metodológico, Lima Vaz identifica o tratamento tomasiano do problema da beatitude com uma oscilação entre, de um lado, as implicações de uma intuição profunda e, de outro, as exigências de uma sistematização científica rigorosa. Do lado da sistematização rigorosa está o aristotelismo efervescente no século XIII, identificando em Aristóteles, segundo a expressão de Léon Robin, uma aliança ambígua de platonismo e empirismo, ${ }^{20}$ aliança essa que fará Tomás de Aquino corrigir Aristóteles em nome da razão mesma, cujas exigências manifestam-se na intuição de Tomás. Do lado dessa intuição, segundo Lima Vaz, está a experiência tomasiana, marcada pela "tensão extrema de duas orientações que atravessavam a especulação helênica e recebiam uma significação nova ao contato da Revelação cristã" ${ }^{21}$

A primeira dessas orientações é a visão do movimento dos seres que sugere uma ascensão e um retorno integrador da multiplicidade a uma unidade primeira na ordem mesma do real. A segunda é a exigência científica que solicita uma determinação rigorosa das ordens da realidade. Essa dialética

\footnotetext{
${ }^{19}$ Cf. DE LUBAC, Surnaturel, op. cit.; RONDET, H. Nature et Surnaturel dans la théologie de Saint Thomas d'Aquin. Recherches de sciences religieuses 33 (1946) 56-91; Gratia Christi - Essai d'histoire du dogme et de théologie dogmatique. Paris: Beauchesne, 1947, p. 200-234. ${ }^{20}$ Cf. LIMA VAZ, H. C. O problema da beatitude, op. cit., p. 8.

${ }^{21}$ Idem, p. 5.
} 
entre ascensão e posição em uma indestrutível consistência própria, possibilitadora da ciência, marca o tratamento grego do tema da beatitude, ao mesmo tempo em que nele introduz uma ambiguidade que se manifestará com agudeza em Aristóteles. Essa mesma ambiguidade levará Tomás de Aquino a separar-se do Filósofo, até porque uma síntese mostrava-se possível, aquela imprevisivelmente oferecida pela Revelação cristã.

A mediação para tal síntese, no que toca ao lado filosófico da problemática, virá do neoplatonismo que conduz o éros dialético de Platão ao êxtase plotiniano, uma das "linhas de força" do pensamento de Tomás, também ela mediada, mas agora pelo pensamento de Dionísio Pseudoareopagita. ${ }^{22}$ Daqui surge outro dado metodológico da análise de Lima Vaz: a consideração da estrutura nitidamente neoplatônica do pensamento tomasiano, sobretudo na Suma de teologia. Ainda do lado filosófico, a mediação do aristotelismo não deixa de ser manifesta, sobretudo por seu caráter científico, mas também por seu "politismo", ${ }^{23}$ quer dizer, a inscrição dos cidadãos felizes na pólis, postura tipicamente grega. Em outras palavras, de Aristóteles Tomás recebe não apenas o rigor dedutivo-científico, mas também a preocupação ética, fundamental à realização humana. No entanto, Tomás identifica na reflexão aristotélica um impasse, o de conceber a virtude como essencialmente social (em fidelidade ao espírito grego) e, ao mesmo tempo, de tratar o sábio ou o feliz como autossuficiente porque capaz de uma contemplação que o satisfaz.

Essa será, em grandes linhas, a razão da recusa tomasiana da concepção aristotélica da beatitude, que não lhe parecia racional, ${ }^{24}$ recusa esta que leva a ver, por conseguinte, o lado experiencial-teológico do pensamento de Tomás de Aquino, que encontrará a mediação da fé e da afirmação do Bem transcendente para solucionar a ambiguidade herdada dos gregos, especialmente do Estagirita. Segundo a exegese de Lima Vaz, o pensamento tomasiano sobre as virtudes naturais e a preocupação em manter a consistência natural do espírito criado com a determinação de um fim também natural permitirão reintroduzir a transcendência na ordem da realização precisamente natural, uma vez que o espírito mostrar-se-á, a um só tempo, como centro consistente em si (e, portanto, condizente com as exigências científico-discursivas) e arrastado pelo pondus (peso) do seu próprio e íntimo Bem, que lhe é transcendente. A contribuição bíblico-cristã, no limite, só resolve o "problema" da beatitude porque não se funda em uma dialética, mas em uma escatologia antecipada que atravessa a História e lhe dá sentido ao permitir um diálogo entre Deus e os humanos.

\footnotetext{
${ }^{22}$ Idem, p. 6.

${ }^{23}$ Idem, p. 9.

${ }^{24}$ Cf. TOMÁS DE AQUINO, Comentário ao Livro das Sentenças de Pedro Lombardo IV, d. 49, q. 1. a. 1, sol. 4 .
} 
O caminho que a análise dos textos tomasianos abre a Lima Vaz consistirá, então, em identificar o modo como Tomás de Aquino, com sua impostação neoplatônica e sua vivência cristã, supera as conclusões relativistas da ética aristotélica, embora aceite seu conteúdo fenomenológico, e reintroduz o eterno no finito, a transcendência na natureza, o sobrenatural no natural.

\section{A fenomenologia da beatitude e o "pedante" teocentrismo de Tomás de Aquino}

Lima Vaz descreve o que identifica na obra de Tomás de Aquino como uma "fenomenologia da beatitude" ou processo mesmo de constituição do pensamento sobre o fim último do ser humano, esclarecendo de saída que por fenomenologia entende, em sentido inteiramente realista, a "descrição dos conteúdos da consciência tais como se apresentam, mesmo se já conduzidos por uma dialética implícita". ${ }^{25}$

Sua abordagem decorre certamente da habilidade ao tratar do que costumava chamar de objetivismo antigo e medieval (em linhas gerais, o compromisso com um juízo afirmativo da existência dos objetos da consciência) a partir de uma concepção da experiência como tentativa de comprovação dos objetos ou de um assegurar-se do sentido deles por um circumenvolver dos objetos por todos os lados. A experiência ou a consciência aparece, assim, como liberta não apenas de um caráter meramente sensível, mas também do vazio das formas puramente racionais: ela corresponde à percepção em geral e à expressão de uma presença, ao modo do que Tomás de Aquino sintetizou no capítulo 59 da Suma contra os gentios, na linha do que já fizera Aristóteles no tratado Sobre a alma III, 430a4: "o inteligente em ato é o inteligível em ato". Como explica o próprio Lima Vaz, em um texto posterior ao manuscrito aqui apresentado, a aparente tautologia dessa expressão aristotélico-tomasiana contém uma intuição forte, pois a presença que se manifesta na experiência não ocupa a consciência ao modo de algo que invade um espaço vazio, mas se dá à medida que a consciência a acolhe e, de certo modo, identifica-se com ela. Conhecer, assim, não será apenas reproduzir algo "exterior", mas um voltar-se da consciência sobre si mesma, donde a dificuldade de falar de experiência sem uma concomitante forma de expressão do objeto pelo sujeito. ${ }^{26}$

${ }^{25}$ Cf. LIMA VAZ, H. C. O problema da beatitude, op. cit., p. 15, n. 22.

${ }^{26}$ Essa visão a respeito da concepção de experiência e consciência em Lima Vaz, dada aqui de maneira excessivamente esquemática, pode ser vista na sua formulação mais genuína em: LIMA VAZ, H. C. Problemas de fronteira (Escritos de Filosofia, vol. I). São Paulo: Loyola, 1986, p. 159-256. 
É dessa perspectiva que Lima Vaz identifica uma marcha de reflexão nas cinco primeiras questões da Prima Secundae (Primeira Parte da Parte II) da Suma de teologia, nas quais se desenvolve o tratamento anteriormente dado na Suma contra os gentios III, 26-55 e posteriormente sintetizadas no Compêndio de teologia, especialmente nos capítulos 104-110, 148-150 e 255. A análise tomasiana do desejo humano ou da busca da beatitude levará o frade dominicano a descrevê-la nos termos da definição aristotélica da operação de contemplação perfeita, com sua consequente deleitação, e da herança neoplatônica do retorno ao Uno, o primeiro princípio, também com o gozo por ele proporcionado. Concomitantemente, a análise do desejo de deleitação ou gozo - com o que o ser humano completa-se precisamente como humano - leva a recusar qualquer carência no objeto da beatitude, pois a preocupação com algum bem ulterior faria o ser humano permanecer em desassossego. A beatitude aparece, então, como perfeição última ou simplesmente como bem perfeito. É nessa linha que Tomás de Aquino, em uma "renúncia otimista", ${ }^{27}$ poderá excluir do objeto da beatitude todo bem que seja de algum modo imperfeito, superando, por uma exigência mesma da razão, o relativismo aristotélico e a autossuficiência de uma contemplação imanente. A suficiência continuará como característica fundamental da beatitude, mas haverá de fluir da transcendência do objeto. Trata-se, no limite, de concretizar o próprio ideal aristotélico da perfeição final da natureza, mas com uma transposição que desproblematiza os mesmos dados postos originalmente por Aristóteles. Em outras palavras, por uma exigência legitimamente racional, como afirma Lima Vaz, "a imanência da operação perfeita implica agora (...) uma espécie de 'humildade ontológica', pois que a sua atuação - o mais íntimo desejo do ser racional - é um dom da parte do objeto, (...) e a visão intelectual floresce em possessão de amor" ${ }^{28}$

A transformação de perspectivas operada por Tomás leva a entender que só na adesão imediata ao Bem Supremo, encontrado como presença e horizonte de realização nas próprias potências humanas naturais, e não por um intermediário conceitual, pode consistir a beatitude. Essa presença ou horizonte de destinação apresenta-se como uma incoação do bem terminal, último, o qual reluz na certeza dada pela experiência e pelo conteúdo da fé. A herança neoplatônica auxilia na superação tomasiana da ambiguidade aristotélica pois, do ponto de vista do retorno, os entes intelectuais não podem ter por objeto da beatitude nada de imperfeito (nem mesmo as substâncias separadas, como defendiam algumas teorias islâmicas), mas somente a visão da divina essência. É a fé cristã de Tomás que age sobre os esquematismos filosóficos produzidos pela conjunção do platonismo empirista de Aristóteles (com sua teoria da virtude e do bem supremo)

\footnotetext{
${ }^{27}$ Cf. LIMA VAZ, H. C. O problema da beatitude, op. cit., p. 17.

${ }^{28}$ Idem, ibidem.
} 
e do neoplatonismo (com a dialética do retorno), levando-o a uma fenomenologia da beatitude centrada na presença atuante do Bem Supremo, perspectiva inteiramente nova para o pensamento grego. Com efeito, de acordo com a Revelação cristã, a visão do Bem Supremo não aparece tanto como télos ou fim visado em um processo exprimível dialeticamente, mas sobretudo como éschaton, termo de uma História que avança sob o signo da livre iniciativa divina.

Fundamentalmente são essas duas perspectivas, helênica e cristã, que Tomás de Aquino faz cruzar em sua descrição da beatitude, enfrentando um problema imediatamente dela decorrente e de solução delicada: "como conciliar a exigência e a incoação do Fim no ser-para-o-fim, implicada em todo o processo dialético de finalidade, com a transcendência absoluta do Fim sobrenatural, transcendência com relação ao ser criado como tal?"29 Em outras palavras, trata-se de equilibrar os polos da transcendência e da imanência, compondo o teocentrismo absoluto da beatitude com a infinita gratuidade do dom divino.

Neste ponto (Parte III do manuscrito), Lima Vaz, com aguda perspicácia e lúcida humildade, desculpa-se junto de seus leitores por recorrer ao termo teocentrismo para caracterizar a novidade da ética tomasiana da beatitude. $\mathrm{O}$ uso desse neologismo, como dizia Henri Brémond, ${ }^{30}$ é marca de um pedantismo terrível, embora, como insiste Lima Vaz, seja também terrivelmente necessário. Não se trata de falar de teocentrismo cultural, como fazem muitos manuais de história do pensamento europeu ao dizerem que a Idade Média (e, por conseguinte, Tomás de Aquino) teria sido um período fundamentalmente teocêntrico. Só por uma imensa dose de presunção ou ignorância alguém continuará, depois das pesquisas históricas dos séculos XIX e XX, a empregar esse neologismo como uma etiqueta para referir-se ao pensamento medieval como algo homogêneo. Em vez disso, Lima Vaz define o teocentrismo como a consideração de Deus como objeto essencial e razão de ser da Beatitude do ser espiritual, um Deus que é transcendência absoluta, fonte do ser que flui perenemente da gratuidade mais pura, e, a um só tempo, amor substancial, autor de uma graça que, por sua vez, é o termo de uma História que Deus empenhou-se em livremente traçar.

Todavia, se a beatitude é absolutamente transcendente em relação ao espírito inteligente criado (não divino por natureza, mas divinizável, sem no entanto igualar-se ao transcendente), é porque esse espírito é também natureza, o que, em termos aristotélicos, significa a orientação para uma beatitude final rigorosamente exigida na linha de sua finalidade própria. Henri de Lubac, diante dessa posição do problema, apresenta a solução

${ }^{29}$ Idem, p. 24.

${ }^{30}$ Cf. BREMOND, H. La querelle du pur amour au temps de Louis XIII. Paris: Bloud \& Gay, 1932, p. 15. 
tomasiana como um compromisso instável entre duas posições antinômicas: a helênica e a bíblica. Por conseguinte, ele defende que um aprofundamento da posição tomasiana em sua lógica interna conduziria à negação da transcendência do sobrenatural. Lima Vaz, por sua vez, evitando buscar a priori uma posição sistematicamente definida no pensamento de Tomás, empenha-se em elaborar uma reconstituição das linhas de força da arquitetônica textual do frade dominicano e encontra a possibilidade de equilibrar os diversos elementos em uma unidade viva que se caracteriza pelo senso mais agudo da natureza da oposição, por um lado, entre transcendência do fim sobrenatural e dinamismo imanente à própria natureza, e, por outro lado, entre as duas vertentes, ascendente e descendente, do mesmo teocentrismo. ${ }^{31}$

Por uma análise cerrada dos textos tomasianos, e em debate direto com a interpretação de De Lubac (e outros), Lima Vaz encontra em Tomás a mediação do Universo como elemento fundamental que dá à beatitude, vista sob a perspectiva da pressuposta antinomia aqui citada, todo o seu sentido e o seu alcance. É por meio do Universo que o espírito, como natureza criada, entra em relação com Deus, aparentemente longínquo, e atinge assim o seu fim propriamente natural. Na bela fórmula de Lima Vaz, "em certo sentido todas as virtudes naturais são, para Santo Tomás, virtudes políticas, mas aqui a pólis se alarga à dimensão do Universo", ${ }^{32}$ tal como se observa na Secunda Secundae q. 26, a. 3. A realidade, encarada sob a influência do aristotelismo, faz ver que as virtudes e o fim natural, no sentido tomasiano, são incapazes de fundar um personalismo, um diálogo entre pessoas (a humana e as divinas), mas é então que Tomás chega à sua própria e verdadeira perspectiva, respondendo à problemática tipicamente aristotélica. Santo Tomás mantém a natureza espiritual em sua consistência própria, como natureza, a qual, aparecendo em um Universo ordenado, um todo, mostra-se primeiramente como capaz de integrar-se, pelo seu dinamismo próprio, ao ritmo desse Universo. Numa palavra, a verdadeira dignidade, o verdadeiro bem do espírito, é dom de Deus; e é só por meio da aceitação desse dom que o espírito pode atingir a Deus, Deus próximo, vivenciando a incoação da beatitude perfeita nos termos da parousía (parusia) evangélica. O esquematismo neoplatônico da busca do Uno permite a Tomás descrever a processão e o retorno dos entes ao seu princípio, tal como o Universo o manifesta, insistindo que esse retorno consuma-se quando a criatura espiritual, precisamente como tal, atinge a Deus. O desejo natural da beatitude será, por conseguinte, o fio condutor que permite a Tomás unificar numa só visão os dois planos da natureza e da graça, revelando assim o autêntico caráter de seu teocentrismo absoluto da beatitude. Tal desejo, enfim, se desloca para uma região mais profunda, não somente psíquica, mas ontológica.

\footnotetext{
${ }^{31}$ Cf. LIMA VAZ, H. C. O problema da beatitude, op. cit., p. 27.

${ }^{32}$ Idem, p. 41.
} 


\section{Natureza, espirito, Deus}

A encruzilhada filosófica, nas palavras de Lima $\mathrm{Vaz}_{,}^{33}$ a que chegam os intérpretes de Santo Tomás é a questão da relação entre o desejo natural de Deus (o teocentrismo tomasiano) e o fim sobrenatural do ponto de vista da realização desse fim. Trata-se de "determinar se Santo Tomás, a partir do desejo natural, estabelece de direito a visão de Deus como fim definitivo e único do espírito ou somente sua possibilidade teórica" ${ }^{34}$

A filosofia aristotélica oferecia a Tomás a descrição do espírito como ser no Universo, devendo, por isso, ser antes de tudo natureza. Mas, se a natureza aristotélica oferece, entre outras coisas, uma base para a marcha do ideal científico, ela parece opor-se a um retorno real do ente ao seu princípio, uma vez que a contemplação do sábio, fim mais alto da natureza, é um contato puramente formal com a Causa Primeira. Já para Santo Tomás, o amor natural ou o desejo do princípio faz que o Universo apareça como um teotropismo, um todo em que a inclinação para Deus equivale à prevalência do bem do todo sobre o bem das partes. Essa inclinação permanece imanente ao Universo e é sua linha de equilíbrio. Em vez, porém, de manter-se no registro neoplatônico de uma união entendida nos termos de uma mística intelectualista, Tomás encontrará na experiência cristã uma forma de superar a antinomia que agora se explica por mostrar a perspectiva exclusivamente dialética de seu ponto de partida: se o fim aparece como télos, ele é objeto de uma conquista da inteligência, suprema ambição da "alma grega". ${ }^{35}$ Todavia, a partir do finito real, a inteligência só pode atingir um infinito formal, infinitamente longe do cume ao qual o esforço dialético pode chegar, não satisfazendo ao ideal eudaimonista de chegada a um bem perfeito, sem carência, e mantendo a inquietação do espírito que, no entanto, vislumbra naturalmente a possibilidade de possuir tal bem. "Desilusão mortal" ${ }^{36}$ Já a experiência cristã apresenta uma visão radicalmente diferente, pois Deus aparece no início e no fim não de um processo dialético, mas de uma História; é dele a iniciativa suprema, de modo que o fim, agora, é éschaton, posição absoluta como dom gratuito. A transcendência do fim, em sentido cristão, está na origem da dimensão vertical do pensamento tomasiano à qual Lima Vaz denomina "teocentrismo do espírito". ${ }^{37}$

O espírito, sob a perspectiva da descrição da experiência cristã, corresponde a uma dimensão profunda que é o ponto de apoio da destinação divina. Ele se torna, pois, o objeto de uma visão religioso-teológica por sua abertura para o dom divino, abertura que requer liberdade; e o dom divino não é

${ }^{33}$ Cf. idem, p. 64.

${ }^{34}$ Idem, ibidem.

${ }^{35}$ Idem, p. 68.

${ }^{36}$ Idem, ibidem.

${ }^{37}$ Idem, ibidem. 
exigência, mas expectação. A estrutura ontológica do espírito, situado entre a natureza e a graça, revela-se como sujeito ou suporte do desejo natural de Deus e é certamente anterior ao dom da graça santificante (aquela que o eleva à beatitude). A irredutibilidade do espírito ao sistema científico do mundo, em termos aristotélicos, levou Tomás de Aquino, com categorias aristotélicas, a prolongar sua visão em um sentido religioso ou teológico que, não sendo ainda teologia propriamente dita, é filosofia religiosa existencial e concreta. "A realidade do espírito impõe-se a Santo Tomás por meio do homem tal como é dado na História." ${ }^{38}$ Justificando-se quanto ao seu uso do termo espirito (ligeiramente diferente do uso tomasiano de spiritus, embora fiel a ele), Lima Vaz afirma que o espírito é desejo de Deus a um só tempo absoluto e condicionado: absoluto, não no sentido de uma exigência dialética absoluta do fim no ser-para-o-fim, mas no sentido de uma posição absoluta do fim no termo da História em que o espírito está empenhado (condicionado), com a misteriosa antecipação desse mesmo fim no seio do acontecer histórico.

\section{Conclusão}

Seria inadequado pretender resumir aqui a conclusão a que chega o manuscrito de Lima Vaz, dando crer aos leitores que essa breve apresentação reproduziu a sua riqueza de intuições, análises, interpretações e debates com comentadores de Tomás de Aquino. Somente um estudo atento do próprio manuscrito pode permitir avaliar sua originalidade.

No entanto, apenas para enfatizar o que talvez tenha sido o coração da exegese de Lima Vaz do tratamento tomasiano da beatitude, seja permitido insistir no modo como, em sua Conclusão, ele retoma o que chama de "dois olhares da razão": $: 39$ em contato com a realidade, a razão natural sente-se na terra firme do ser, elaborando noções e construindo visões sistemáticas, sem, no entanto, atingir o mistério mesmo da realidade, donde a contingência dos sistemas filosóficos (pois eles não podem pretender substituir-se à realidade mesma), bem como a necessidade deles (pois eles são o meio indispensável de expressão de nossa razão abstrativa e participam da absoluta necessidade do ser). No contato, porém, com a transcendência pessoal, por meio do qual se pode estabelecer um diálogo e uma realização não apenas intelectual, mas também afetiva, a mesma razão natural identifica no ser humano e para o ser humano um "centro de nós mesmos" ${ }^{40}$ e tal centro é o signo da transformação que a Revelação cristã operou na faculdade e no objeto do nosso conhecer.

\footnotetext{
38 Idem, p. 70.

39 Idem, p. 75-76.

${ }^{40}$ Idem, p. 75.
} 
Se, porém, há dois olhares da razão, não há, entretanto, dois mundos. O objeto próprio dos sistemas é a interpretação do mundo, mas do mundo como schêma (figura ou aparência, como, aliás, diz Paulo, em 1Cor 7, 31); e esse "mundo", como tal, deve passar. No entanto, esse mesmo mundo, cuja ordenação imanente a razão científica tende a reconstruir em si, aparece à razão cristã como orientado, e em uma dimensão em profundidade. Ele se mostra, a partir do caráter experiencial da fé, como signo essencial de realidades mais profundas, cuja expectação se dá como em um "incessante trabalho de parturição dos novos céus e da terra nova (cf. Rom 8, 19-22)" ${ }^{41}$ A razão cristã move-se, assim, em um Universo sacral, tal como era o Universo de Santo Tomás, e, explorando latências do pensamento tomasiano, Lima Vaz defende que o humanismo cristão não é uma simples sublimação do "ser humano natural", ou seja, do ser humano "coisa da natureza" ou parte imanente de um universo científico, tal como a razão, deixada a si mesma, pode concebê-lo. O humanismo cristão implica a revelação da imagem de Deus no ser humano, a sua destinação transcendente e, portanto, o seu valor como pessoa.

Por fim, sem pretender aprofundar os debates do século XX em torno de uma filosofia cristã, Lima Vaz defende que ela começa quando a razão mesma se transforma, quando renasce pelo olhar que a experiência cristã permite lançar às coisas. Trata-se de um olhar de pessoa a pessoa em um clima de amor, algo de um plano não simplesmente empírico nem experimental-científico, mas experiencial: experiência do Sagrado como tal, na qual a presença de Deus é mediada por um signo, o ato religioso mesmo. Experiência, aliás, que traz para o ser humano um aprofundamento essencial de si mesmo, sobretudo quando identifica em si a presença divina (e não simplesmente uma ideia), como esperança e também já como posse. A novitas Christi (novidade de Cristo) foi, numa palavra, o que permitiu a Tomás resolver o problema da beatitude tal como configurado pela ambiguidade grega e ancorar-se na mais aguda consciência de que essa solução é um aprofundamento na compreensão da própria natureza, do mundo e de Deus, aprofundamento jamais terminado, pois seu objeto é uma verdade inexaurível.

Endereço do Autor:

Universidade Federal de São Paulo

Campus de Guarulhos

Estrada do Caminho Velho, 333 - Jardim Nova Cidade

07252-312 Guarulhos - SP

${ }^{41}$ Idem, p. 76. 